\title{
On the frontline-Sustainability and development research amidst the COVID-19 pandemic
}

Andrea Gatto ( $\square$ a.gatto@greenwich.ac.uk)

Natural Resources Institute, University of Greenwich https://orcid.org/0000-0003-1005-3571

Carlo Drago

University Niccolò Cusano

Matteo Ruggeri

Istituto Superiore di Sanità

\section{Analysis}

Keywords: COVID-19, sustainability, development, Coronavirus, pandemics, bibliometrics

Posted Date: November 20th, 2020

DOl: https://doi.org/10.21203/rs.3.rs-103974/v1

License: (c) (i) This work is licensed under a Creative Commons Attribution 4.0 International License.

Read Full License 


\section{Abstract}

COVID-19 outbreak has exposed the world population to a condition of unprecedented public health and global health vulnerability. Preliminary and projected consequences have exhibited their harmfulness for socio-economic, environmental and political systems. In this framework, development and sustainability turn focal policy targets to limit the humanitarian and ecosystems impacts of the pandemic and stimulate mitigation, preparedness and adaptation to change. This work aims at furnishing a prompt array of key tools to analyse, comprehend and disentangle the sketched issues. For this scope, it is conducted a bibliometric analysis for depicting and mapping the early scholarship response on the relationship between the 2019 Coronavirus, sustainability and development within the pandemics discourse. The research finds a relevant bulk of early publications and geographical insights, principally published on environmental and economic policy, global and public health journals by US, UK, Chinese and Italian scholars. Exploiting a multiple correspondence analysis and a validated cluster analysis, the investigation detects a conceptual structural map made up of clusters of issues - environmental health, socio-economic and medical/technical topics, that can be related to the different phases of the Coronavirus. The outputs confirm the need for rapid sustainability action within the development policy to contrast the pandemic.

\section{Coronavirus And Pandemics Disentangled-the Increasing Need For Sustainability And Development Trajectories}

Pandemics and infectious disease hinder worldwide development (Jonas, 2013; Brahmbhatt and Dutta, 2008; WHO, 1996; Becker, 1990). Pandemics have been causing grand socio-economic and ecological disruptions, hampering inequalities and poverty, especially amongst people living in extreme poverty (Loayza and Pennings, 2020; Sumner et al., 2020; Hofrichter, 2003; Benatar, 2002). Major epidemics and pandemics have hit specific regions or worldwide vulnerable people from both the Global North and South throughout the last century (Yuh and Gatto, 2020). Some of the harshest outbreaks include infectious diseases and coronaviruses such as the Spanish flu, the 1957-1958 Asian influenza, the Ebola virus group, the SARS and the COVID-19. Conversely from the former, the 2019 Coronavirus is different for its community spread and severity - factors changing daily life and affecting both short- and long-term development (WHO, 2020a).

Public, global and environmental health are intertwined with sustainability and development (Di Marco et al., 2020). This is particularly true for resource governance, their vulnerability and resilience, where protection from food, energy and water shocks turn to be nodal sectors (Gatto and Drago, 2020a; Morrow et al., 2019; Melo and Gatto, 2014). Vulnerability to shocks and major events are likely to affect complex systems (Gatto and Busato, 2020) as long as vulnerability to pandemics must be understood through an overarching view on global complex systems, contemplating institutional instability (Benatar, 2002). Monitoring the repercussions on the vulnerable is paramount to understand the likelihood for them to fall into socio-economic traps. This aspect is particularly frail for the global consequences that might be reflected on the global macroeconomic front (Abel and Gietel-Basten, 2020). 
Geographic proximity and location have shown to deserve thorough and analytical academic investigation. This involves the study and visualisation of contagions spread (Zhou et al., 2020), countries and modalities of the actions to tackle the virus (Wei et al., 2020), as well as the social distancing and people's movements dynamics (Zhai et al., 2020) and migrants workflows (Abel and Gietel-Basten, 2020). All these spatial aspects return prime socio-economic inequality results, relevant for COVID-19 development research and policy investigation.

Food and nutrition security encase overriding and delicate sectors during pandemics and infectious disease outbreaks, and COVID-19 is no exception (Phillipson et al., 2020). These affect both supply and demand sides and hit diverse geographical locations, as well as the health and socio-economic possibilities of the foreigner and migrant agriculture workers (WEF, 2020). Food must be framed into complexity, where sound data and information are required to deliver solid policy and decisionmaking (Mock et al., 2013). Food sustainability is a determinant factor for ensuring development and environmental and global health, facilitating major consequences, alleviation and smoothing risk and adverse events (Agovino et al., 2018). Above all, food production and value chain practices have shown to be focal amidst the COVID-19 occurrence (Cattivelli and Rusciano, 2020). They are likely to come up with the opportunity of delivering fungible applications for a food transition envisaging sustainable consumption patterns (Cohen, 2020).

The scientific proliferation in the novel Coronavirus disease confirms the importance of detecting the research dynamics amidst the outbreak (Duan et al., 2020). Disentangling cooperation networks, scholars and publication results with respect to geographical location

This research note aims at analysing existing publications on the emerging COVID-19, connecting them with sustainability and development research topics. To investigate this nexus, the work in hand exploits an up-to-date bibliometric analysis on the publication records on these themes. The work also drafts policy recommendations for the way forward, rooted in resilience action, with the aim to provide preparedness for upcoming pandemics and global health disruptions.

\section{Navigating The Unknown-resilience Preparedness And Mitigation For The Vulnerable}

As for precedent viruses, the COVID-19 disease is likely to have originated from zoonotic spillover infections and transmissions coming from animal species (Zhang, 2020; Jones et al., 2008). This fact raises major concerns about biological hazards and pandemics and calls for resilience preparedness and systemic view for international governance (Djalante et al., 2020; FAO, OIE, WHO, UN System Influenza Coordination, UNICEF and World Bank, 2008). As a massive-scale ongoing pandemics episode, the 2019 Coronavirus is a prime adverse event necessitating holistic perspectives and systemic outlooks to foster resilient and sustainable governance intervention (Gatto, 2020). Tackling this unexpected situation is nowadays a challenge that our society is urgently required to govern for preserving sustainability (Pirouz et al., 2020). Novel policy responses to pandemics demand sustainability action to adapt and minimise 
socio-economic, ecological and institutional downturns. The process is mutual: on the same wavelength, the sustainable development agenda needs to adjust its priorities and consider the possibility of upcoming pandemics, easing global health programmes (Di Marco et al., 2020; Bogich et al., 2012).

Poor and vulnerable people are the most exposed to (natural) hazards (World Bank, 2012). They are the most likely to get hit by infections and major disease and to experience severe socio-economic consequences, to get structurally worsening their life and health conditions and die. The most affected categories include women, the elderly, people with disabilities and illnesses and minorities at risk, principally located in remote rural areas of the Global South (Lloyd et al., 2020; Loyaza and Pennings, 2020; Sumner et al., 2020). The COVID-19 contagions and consequences risk becoming a plague in developing countries and for the migrants, due to the frequent inadequate levels of public health and social nets, lack of preparedness, multifaceted vulnerability and further systemic deficiencies that they are often connotated by (Gilbert et al., 2020; Loayza and Pennings, 2020; Abel and Gietel-Basten, 2020).

When it comes to unfolding pandemics impacts, the economy-health nexus turns paramount. This aspect also reflects the significance of health within the broader development. It is no news that health dynamics - summarised as life expectancy - is one of the three pillars of human development, along with the economy - GNI - and education - schooling (UNDP, 2010). The importance of entailing the capability approach to investigate pandemics and find sustainability and development policy recommendations arises. Human development established holistic outlooks to explore development and is strictly tight with sustainable development due to its multifaceted perspective and inter-generational equity component (Gatto, 2020). Human development propensity to strive for reducing vulnerability through resilience policies and practical action (Malik, 2014) underlies the interconnectedness between development, sustainability and pandemics and paves the way for global access to health and health justice (Venkatapuram, 2013).

\section{Bibliometrics And Cluster Maps Of Development And Sustainability Amidst The Covid-19 Pandemic}

The scope of bibliometrics is to examine the relevance and the impact of published works (Iftikhar et al. 2019). A bibliometric analysis is useful to evaluate the research trends, the most relevant topics on a research corpus and also the cooperation networks between different authors. Previous studies have assessed the effectiveness of bibliometric explorations to summarise large research corpora define, examine and disseminate complex phenomena (Gatto and Drago, 2020b; Ho and Gatto, 2020). Bibliometrics is particularly worth to portray scientific advances and delineate the main undertaken guidelines (Aria and Cuccurullo, 2017). The method is also useful for identifying and discover new research insights from actual trends, being worth to synthesise the existent research and mapping the actual knowledge on a specific topic (Zhang et al., 2019; Cobo et al., 2015).

This work analyses up-to-date COVID-19 research related to development and sustainability. The whole techniques and methodological steps undertaken are explained in detail in Appendix A. 
Previous scholars have mapped research networks on the 2019 Coronavirus (Duan et al., 2020). The study in hand made use of a second technique to depict current publications on COVID-19, development and sustainability. Namely, multiple correspondence analysis and validation clustering exercises on key terms were performed. This step was necessary to provide a clearer picture of trendy research topics on the issues - first cluster. The second cluster has been used to corroborate the precedent results and analyses. The figures and details of the conceptual cluster maps can be found in Figure1, Figure 2 and

\section{Appendix B.}

\section{Key Points-what Is Scholarship Showing?}

From the main information about data, it is possible to identify some descriptive information on this strand of research. It is fundamental to sketch the number of documents (300), statistical sources (168), keywords (817) used in the literature on a period of 17 years circa (2003-2020). The average citation for the documents is 9.301. The second part of these statistics allow to better understand the characteristics of the cooperation in the analysed literature: there emerge 35 authors of single-authored documents; 806 authors of multi-authored documents; and 52 single-authored documents. From these statistics, it is also possible to compute some relevant indexes: the number of documents per author is 0.364 , whereas there are 2.75 authors per document and a cooperation index of 3.17.

This study took into account existing publications on different Coronaviruses with respect to sustainability and development. Due to the greater impact of COVID-19, the larger number of overall worldwide scholarship and increasing research interest in various interconnections of the former with sustainability and development studies, the scientific production of these works strongly increased from the year 2019 to the first part of 2020. In particular, in the year 2020, there was an increase to 10 times of scientific production with respect to 2019 . The work produced and published are mostly research articles (186) but 56 reviews shall also be noticed. The most prolific authors are: Haghshenas SS (12 articles); and Gautam S and Pirouz B (9 articles per each). It shall also be remarked the structure of international cooperation on this research. It is interesting to note that the most prolific countries in producing these articles are USA, Italy, China and the United Kingdom (total citations by country). At the same time the USA, the United Kingdom and South Africa show the highest numbers of citations on the studies considered (total citations by country).

The relevant topics considered in the publications can be well represented by the keywords and the keywords-plus considered. It is possible to observe a mixture of different topics which relate to pandemics and Covid-19 and broadly to Coronavirus. Climate change also got high relevance, signalling as the trendiest keyword. This fact is interesting because reveals that the literature tends to investigate the outbreak of the pandemic inside the larger phenomena connected to climate change. At the same time, it is not surprising that one of the most used keywords is China. When it comes to keyword-plus in this line of literature, one shall notate an emphasis on the role of humans. More detailly, central is the role of humans and the human, as well as public health and China. 
The results are sketched in Appendix A.

Further results shall be highlighted from the cluster conceptual maps.

The examination of the first cluster renders the following observations:

1. The dynamic social aspects and the medical lepidemiological topics in the right of the axis (emergency service and hospital emergency service are useful to interpret the axis). At the same time, there appear a hot topic from the blue cluster representing the epidemiological dynamics - the disease outbreak. This encompasses important elements, such as the organisation of healthcare (and leadership) and healthcare quality.

2. On the left, there emerge the economics of the pandemic - thus, the relevant topics related to the control of the pandemic appear as well.

The different terms are grouped in 3 distinct clusters where the number is automatically selected on the K-Means procedure (the unsupervised algorithm chosen to cluster the different terms by evaluating their coordinates). A possible interpretation of the clusters is that the green is associated with medical topics, the blue with epidemiological themes, and the red cluster regroups salient socio-economic issues which can be reviewed in this literature.

It is worthy to interpret the second axis. Higher values of the axis (at the top of the conceptual structure map) are concepts related to genetics, healthcare systems, food safety, respiratory disease and meat consumption. These elements are considered undoubtedly hot-button issues considering the medical side and return important messages in terms of sustainability and development scholarship. On the other side, it is interesting to note that the lowest values for the axis recall environmental factors like humidity, relative humidity and environmental impact. These outputs are additional pieces of information to corroborate the importance of sustainability and development research within the pandemics and COVID19 array. These paramount results are telling that different characteristics for the spread of the pandemic exist. The shape of the red cluster means that socio-economic factors can also be interpreted as suitable factors on reducing or increasing the spread of the pandemic.

Overall, one can interpret the first axis as the structure of the pandemic emphasising the characteristics of the pandemic, and the second axis the studies focusing on some hot issues on the dynamics.

Of primary order is the left of the first axis, in which one can observe different elements pertaining to economic development, environmental policy, sustainability and urban planning. It is possible to see that these topics are strongly associated with the disease spread. Therefore, air quality, land use, and consumption behaviour can acquire cardinality as the disease spreads. Another key point is artificial intelligence, coupled with classification methods and new technologies. The robustness analysis performed on 5 clusters is useful to better represent emerging topics in a lower number of documents than the first analysis. It shows two emerging topics: artificial intelligence (Al) and gender issues (female) related to the pandemics. This piece of evidence also calls for increasing research on the role of the 
vulnerable within the pandemics. The whole results from the robustness analysis are summed up in Appendix A.

The whole outputs are sketched in Appendix B.

\section{Lessons Learnt-the Black Swan And The Breakthrough}

This work scrutinised early research on the existing relationship between COVID-19, sustainability and development. The study had the scope of mapping scholarly directions and to investigate prospective advances. For this purpose, a bibliometric merged dataset including relevant searches on Coronavirus, Covid-19, Covid and Sustainability and Development has been investigated. On these bases, the paper drew selected short- and long-run policy implications to face the emergency and embrace sustainability and development schemes.

The bibliometric analyses exploited rendered an array of significative results: research on COVID-19 sharply increased with respect to past Coronavirus infections, underpinned by a considerable bulk of scholarship in sustainability and development subjects. Principal vectors pivoting COVID-19 publications include medical, technical, socio-economic and sustainability factors. As a result, this merged database allows exploring the linkages between the pandemic, the environment, health policy and the organisation useful in disease control.

Making use of both exploratory data analysis and multidimensional data analysis techniques, this research identified the different "core" of the literature. In particular, one can observe three foremost clusters which seem to classify the trend information in the literature: firstly, epidemiological, medical and organisational, and health policies useful in disease control; secondly, environmental and medical issues; lastly, socio-economic circumstances which can be prime drivers to the spread of the disease. These socio-economic factors can be analysed through a policy lens, and allow to speculate relevant research hypotheses. This fact would address the consolidated pulsing development policy request to prioritise infectious disease fight and public health support within the global development agenda (UN, 2015; WHO, 1996).

The bibliometric analysis performed synthesises the actual literature on COVID-19, development and sustainability. However, the analysis needs to be addressed in the identification of the array of policy solutions and alternatives proposed in the studies reviewed. For each issue within the conceptual maps, different trade-offs are identifiable by exploring the existing literature. Relevant examples of trade-offs detected from the conceptual maps are:

1. Social distancing with contact tracing vs total lockdown (see "disease control").

2. Hospital admission vs monitoring at the home of the patients with not severe illness ("organization and management").

3. Vaccine research vs. research on the treatment ("major clinical study"). 
It shall be noticed that the proximity of the terms on the conceptual map indicates that these words appear on the same studies. Thus, the terms and problems are interconnected logically. For this reason, health policies are typically considered to "control the disease" on a context of "disease outbreak". Similarly, health policies require an effort of "organization and management" to be planned.

This gives the chance to foresight different scenarios. As a tentative technique for policy analysis and assessment, each result significance can be weighted gauging its number of citations. This way, the ultimate research goal will not be solely the descriptive analysis of the emerging themes of literature, yielding a proper prescriptive analysis of optimal policies identified within the publications. This paves the way for further investigation possibilities.

Potential limitations of the work come from the fact that the majority of papers have been published in a limited set of journals/publishers. This implies that specific editorial policies of the journal/publisher are likely to have driven the diverse results - a higher number of publications can inflate the different keywords, for instance.

From the bibliometrics result, it is also clear the criticalness of the vulnerable. For instance, one of the key themes is gender (female Imale in the conceptual map). The concept "female" is strongly related to the theme "health care system", "food safety" and "risk factor". It is interesting that the role of "health care personnel" has a crucial role for both the gender-specific "health care system" and "health care policy"(see Ruggeri et al., 2018). This argument implies a pivotal role for gender policies. It suggests a deep relationship between women in healthcare, that shall lead to an emphasis on germane sectorial policies and dynamics. One might think about salaries, quality of work and practices such as balanced life-work ratios - e.g. dedicated part-time work programmes. On the other hand, the term "risk factor" corroborates this paper's findings on preparedness. Similarly, the word "food safety" links the importance of food within this multidimensional crisis, revealing intriguing gender dynamics.

\section{The Call For Vulnerable-centred Policies And Health Justice}

Preliminary evidence highlight the importance of a solid national health system to tackle the occurring pandemics and adapt to shocks (Legido-Quigley et al., 2020). These eventualities are confirmed by early figures depicting the emergencies or the potential risks faced by some countries - and their citizens lacking a sound public health system (WHO, 2020b; Abel and Gietel-Basten, 2020). The data becomes dramatic when applied to least developed countries, featuring large inequalities and socio-economic sufferings (Loayza and Pennings, 2020; Phillipson et al., 2020; Sumner et al., 2020). Above all, developing countries will bear the brunt the crises originated from the pandemic. COVID-19 is causing even harsher damages to vulnerable households and communities and is likely to be devasting in the short- and longterm - as for or even more than precedent pandemics figures (Loayza and Pennings, 2020; Benatar, 2002).

The interconnectedness of Al and gender within the COVID-19, sustainability and development discourse also arose from the analyses. The former topic underlines the need to encompass Al, the internet of 
things (IOT) and up-to-date ICT and technologies for monitoring, analysing, mapping and preventing risks and the spread of infection (Peeri et al., 2020). The latter theme is of particular importance and confirms the findings of this work, validating the importance of gender studies in disentangling gender vulnerability, the repercussions on women, and the gender gaps and dynamics due to global health and infectious disease (Alon et al., 2020; Wehnham et al., 2020; Flatø et al., 2017; Gilbert and Walker, 2002).

The urgency of the issues been tackled calls for rapid structural socio-economic reversals. This will need contemplating prompt humanitarian action, risk management and mitigation, supported by granular and robust data, information and analyses, put forward at national and global levels (Anderson et al., 2020; Peeri et al., 2020; Jonas, 2013). Prompt scrutiny of the socio-economic consequences of the pandemics is compelling, whereas typical development tools for enhancing the vulnerable resilience is being limited by this interconnected crisis - as for microfinance tools (Abel and Gietel-Basten, 2020).

More profoundly, the crises arise the need for a resurgence of health justice measures supported by novel public health ethics patterns (Benatar, 2002; Beauchamp and Steinbock, 1999; Beauchamp, 1976). The latter will include access to vaccines, health investments and public care to all, yet resilience and preparedness as well, primarily targeting both the vulnerable and developing countries (McKibbin and Fernando, 2020; Yamey et al., 2020).

Sustainability is key for gradually adapting to the new normal, embarking novel unexplored development pathways and yardsticks. As observed (Di Marco, 2020; Hakovirta and Denuwara, 2020), this might require revisiting the whole sustainable development foundations, yielding centrality to human health and pandemics. Suitable global health futures will be grounded on critical preparedness, readiness and response actions (WHO, 2020a). Long-sighted, informed guidance for development policy will be on the frontline of this process, rendering desirable scenarios and adaptation to change in light of the pandemic and interconnected crises evolution.

\section{References}

1. Abel, G., \& Gietel-Basten, S. (2020). International remittance flows and the economic and social consequences of COVID-19. Environment and Planning A: Economy and Space, 0308518X20931111.

2. Agovino, M., Cerciello, M., \& Gatto, A. (2018). Policy efficiency in the field of food sustainability. The adjusted food agriculture and nutrition index. Journal of environmental management, 218, 220-233.

3. Alon, T. M., Doepke, M., Olmstead-Rumsey, J., \& Tertilt, M. (2020). The impact of COVID-19 on gender equality. National Bureau of Economic Research Working Paper Series, (w26947).

4. Anderson, R. M., Heesterbeek, H., Klinkenberg, D., \& Hollingsworth, T. D. (2020). How will countrybased mitigation measures influence the course of the COVID-19 epidemic?. The Lancet, 395(10228), 931-934.

5. Aria, M., Cuccurullo, C. (2017). Bibliometrix: an R-tool for comprehensive science mapping analysis. J. Inf. 11 (4), 959-975 (Elsevier). 
6. Becker, C. M. (1990). The demo-economic impact of the AIDS pandemic in sub-Saharan Africa. World development, 18(12), 1599-1619.

7. Brahmbhatt, M. and Dutta, A. (2008). "On SARS-type Economic Effects during Infectious Disease Outbreaks." World Bank Policy Research Working Paper No. 4466.

8. Beauchamp, D. E. (1976). Public health as social justice. Inquiry, 13(1), 3-14.

9. Beauchamp, D.E., \& Steinbock, B. (Eds.). (1999). New ethics for the public's health. Oxford: Oxford University Press.

10. Benatar, S. R. (2002). The HIV/AIDS pandemic: a sign of instability in a complex global system. The Journal of medicine and philosophy, 27(2), 163-177.

11. Bogich, T. L., Chunara, R., Scales, D., Chan, E., Pinheiro, L. C., Chmura, A. A., ... \& Brownstein, J. S. (2012). Preventing pandemics via international development: a systems approach. PLoS medicine, $9(12)$.

12. Cattivelli, V., \& Rusciano, V. (2020). Social innovation and food provisioning during Covid-19: The case of urban-rural initiatives in Naples province. Sustainability 2020, 12(11), 4444; https://doi.org/10.3390/su12114444.

13. Cobo, M. J., Martínez, M. Á., Gutiérrez-Salcedo, M., Fujita, H., \& Herrera-Viedma, E. (2015). 25 years at Knowledge-based systems: A bibliometric analysis. Knowledge-based systems, 80, 3-13.

14. Cohen, M. J. (2020). Does the COVID-19 outbreak mark the onset of a sustainable consumption transition?. Sustainability: Science, Practice and Policy.

15. Di Marco, M., Baker, M. L., Daszak, P., De Barro, P., Eskew, E. A., Godde, C. M., ... \& Karesh, W. B. (2020). Opinion: Sustainable development must account for pandemic risk. Proceedings of the National Academy of Sciences, 117(8), 3888-3892.

16. Drummond, M. F, Sculpher, M. J., Claxton, K., Stoddard, G. L. \& Torrance, G. L. (2015) Methods for the Economic Evaluation of the Health Care Programmes. Oxford University Press.

17. Duan, D., Chen, Y., \& Zhang, Y. (2020). Who is contributing? Scientific collaborations on COVID-19. Environment and Planning A: Economy and Space, 0308518X20931105.

18. FAO, OIE, WHO, UN System Influenza Coordination, UNICEF, World Bank (2008). Contributing to One World, One Health- A strategic framework for reducing risks of infectious diseases at the animalhuman-ecosystems interface. Strategic framework requested by the Ministerial Conference in New Delhi in December 2007, welcomed by the Ministerial Conference in Sharm El-Sheikh in October 2008, and urged for implementation by the Ministerial Conference in Hanoi in April 2010.

19. Flatø, M., Muttarak, R., \& Pelser, A. (2017). Women, weather, and woes: The triangular dynamics of female-headed households, economic vulnerability, and climate variability in South Africa. World Development, 90, 41-62.

20. Gatto, A., \& Busato, F. (2020). Energy vulnerability around the world: The global energy vulnerability index (GEVI). Journal of Cleaner Production, 253, 118691. 
21. Gatto, A., \& Drago, C. (2020). Measuring and modeling energy resilience. Ecological Economics, 172, 106527.

22. Gatto, A., \& Drago, C. (2020b). A taxonomy of energy resilience. Energy Policy, 136, 111007.

23. Gatto, A. (2020). A pluralistic approach to economic and business sustainability: A critical metasynthesis of foundations, metrics, and evidence of human and local development. Corporate Social Responsibility and Environmental Management.

24. Gilbert, L., \& Walker, L. (2002). Treading the path of least resistance: HIV/AIDS and social inequalities -a South African case study. Social science \& medicine, 54(7), 1093-1110.

25. Gilbert, M., Pullano, G., Pinotti, F., Valdano, E., Poletto, C., Boëlle, P. Y., ... \& Gutierrez, B. (2020). Preparedness and vulnerability of African countries against importations of COVID-19: a modelling study. The Lancet, 395(10227), 871-877.

26. Greenacre, M., \& Blasius, J. (Eds.). (2006). Multiple correspondence analysis and related methods. CRC press.

27. Hakovirta, M., \& Denuwara, N. (2020). How COVID-19 redefines the concept of sustainability. Sustainability 2020, 12(9), 3727. https://doi.org/10.3390/su12093727.

28. Ho, Y. S, \& Gatto, A. (2020). A Bibliometric Analysis of COVID-19 Research. Under review, Nature.

29. Hofrichter, R. (Ed.). (2003). Health and social justice: Politics, ideology, and inequity in the distribution of disease (Vol. 11). Jossey-Bass.

30. Iftikhar, P. M., Ali, F., Faisaluddin, M., Khayyat, A., De Sa, M. D. G., \& Rao, T. (2019). A bibliometric analysis of the top 30 most-cited articles in gestational diabetes mellitus literature (1946-2019). Cureus, 11(2).

31. Jonas, O. B. (2013). Pandemic risk. The World Development Report, 2014. The World Bank.

32. Jones, K. E., Patel, N. G., Levy, M. A., Storeygard, A., Balk, D., Gittleman, J. L., \& Daszak, P. (2008). Global trends in emerging infectious diseases. Nature, 451(7181), 990-993.

33. Legido-Quigley, H., Asgari, N., Teo, Y. Y., Leung, G. M., Oshitani, H., Fukuda, K., ... \& Heymann, D. (2020). Are high-performing health systems resilient against the COVID-19 epidemic?. The Lancet, 395(10227), 848-850.

34. Lloyd-Sherlock, P., Ebrahim, S., Geffen, L., \& McKee, M. (2020). Bearing the brunt of covid-19: older people in low and middle income countries.

35. Loayza, N. V., \& Pennings, S. (2020). Macroeconomic policy in the time of COVID-19: A primer for developing countries. The World Bank, Washington.

36. Malik, K. (2014). Human development report 2014: Sustaining human progress: Reducing vulnerabilities and building resilience. United Nations Development Programme, New York.

37. McKibbin, W. J., \& Fernando, R. (2020). The global macroeconomic impacts of COVID-19: Seven scenarios. CAMA Working Paper 19/2020, Australian National University, February 2020.

38. Melo, M. P., \& Gatto, A. (2014). Água como bem comum no quadro da governança democrática: algumas reflexões críticas a partir das bases da economia ecológica e sobre a necessidade de um 
novo direito público. Novos Estudos Jurídicos, 19(1), 95-121.

39. Mock, N., Morrow, N., \& Papendieck, A. (2013). From complexity to food security decision-support: Novel methods of assessment and their role in enhancing the timeliness and relevance of food and nutrition security information. Global Food Security, 2(1), 41-49.

40. Moed H. F. (2012) The use of Big Datasets in bibliometric research. Research Trends https://www.researchtrends.com/issue-30-september-2012/the-use-of-big-datasets-in-bibliometricresearch/ Page accessed the 24/5/2020

41. Morrow, N., Salvati, L., Colantoni, A., \& Mock, N. (2018). Rooting the Future; On-Farm Trees' Contribution to Household Energy Security and Asset Creation as a Resilient Development PathwayEvidence from a 20-Year Panel in Rural Ethiopia. Sustainability, 10(12), 4716.

42. Peeri, N. C., Shrestha, N., Rahman, M. S., Zaki, R., Tan, Z., Bibi, S., ... \& Haque, U. (2020). The SARS, MERS and novel coronavirus (COVID-19) epidemics, the newest and biggest global health threats: what lessons have we learned?. International journal of epidemiology.

43. Phillipson, J., Gorton, M., Turner, R., Shucksmith, M., Aitken-McDermott, K., Areal, F., ... \& Monteiro, D. S. (2020). The COVID-19 Pandemic and Its Implications for Rural Economies. Sustainability, 12(10), 3973.

44. Pirouz, B., Shaffiee Haghshenas, S., Shaffiee Haghshenas, S., \& Piro, P. (2020). Investigating a serious challenge in the sustainable development process: analysis of confirmed cases of COVID-19 (new type of coronavirus) through a binary classification using artificial intelligence and regression analysis. Sustainability, 12(6), 2427.

45. Ruggeri M., Drago C., Moramarco V., Coretti S., Koppen J., Islam M. K., Gibson J., Busse R., Van Exel J., Sutton M., Askildsen J. E., Bond C. E., Elliot R.F. on behalf of the MUNROS team (2018) New professional roles and patient satisfaction: evidence from a European survey along three clinical pathways. Health Policy, 122(10), 1078-1084.

46. Sumner, A., Hoy, C., \& Ortiz-Juarez, E. (2020). Estimates of the Impact of COVID-19 on Global Poverty. UNU-WIDER, April, 800-9.

47. 2010. Human Development Report 2010: The Real Wealth of Nations - Pathways to Human Development. New York. http://hdr.undp.org/en/content/human-development-report-2010.

48. United Nations (2015). Transforming our world: the 2030 Agenda for Sustainable Development. A/RES/70/1, New York.

49. Venkatapuram, S. (2013). Health justice: An argument from the capabilities approach. John Wiley \& Sons.

50. Wei, X., Wang, M., \& Kraak, M. J. (2020). Where we are in fighting against COVID-19. Environment and Planning A: Economy and Space, 0308518X20931515.

51. Wenham, C., Smith, J., \& Morgan, R. (2020). COVID-19: the gendered impacts of the outbreak. The Lancet, 395(10227), 846-848.

52. World Bank (2012). The Sendai Report : Managing Disaster Risks for a Resilient Future. World Bank, Washington, DC. 
53. WEF (2020) How COVID-19 is Throttling Vital Global Migration Flows. Cologny: World Economic Forum. Available at: https://www.weforum.org/agenda/2020/04/covid-19-is-throttling-vitalmigration-flows/.

54. World Health Organization. (2020a). Critical preparedness, readiness and response actions for COVID-19: interim guidance, 22 March 2020.

55. World Health Organization. (2020b). Coronavirus disease 2019 (COVID-19): situation report, 57.

56. World Health Organization. (1996). Fighting disease, fostering development. World Health Report 1996. Geneva.

1. Yamey, G., Schäferhoff, M., Hatchett, R., Pate, M., Zhao, F., \& McDade, K. K. (2020). Ensuring global access to COVID-19 vaccines. The Lancet, 395(10234), 1405-1406.

2. Zhai, W., Liu, M., \& Peng, Z. R. (2020). Social distancing and inequality in the United States amid COVID-19 outbreak. Environment and Planning A: Economy and Space, $0308518 X 20932576$.

3. Zhang, X. (2020). Epidemiology of Covid-19. The New England journal of medicine, 382(19).

4. Zhang, X., Estoque, R. C., Xie, H., Murayama, Y., \& Ranagalage, M. (2019). Bibliometric analysis of highly cited articles on ecosystem services. PloS one, 14(2).

5. Zhou, L., Li, S., \& Li, C. (2020). Visualising the dynamics of COVID-19 cases leading to inbound transmission in Hong Kong. Environment and Planning A: Economy and Space, 0308518X20961395.

\section{Figures}




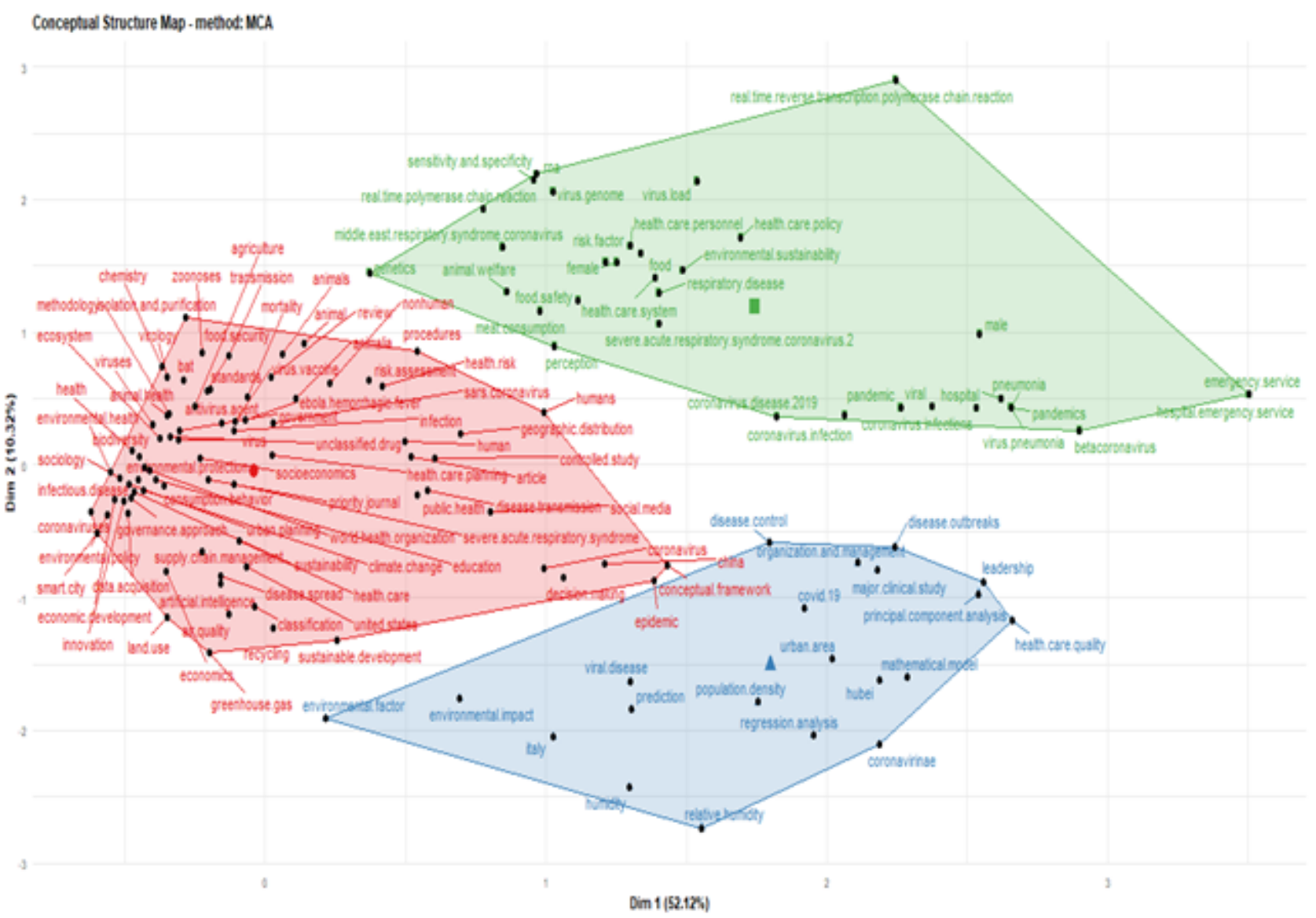

Figure 1

MCA Procedure with clustering validation (3 clusters identified)

\section{Supplementary Files}

This is a list of supplementary files associated with this preprint. Click to download.

- AppendixA.docx

- AppendixB.docx 